\title{
2019 Novel coronavirus: where we are and what we know
}

\author{
Zhangkai J. Cheng ${ }^{1,2} \cdot$ Jing Shan ${ }^{3}$
}

Received: 31 January 2020 / Accepted: 7 February 2020 / Published online: 18 February 2020

c) Springer-Verlag GmbH Germany, part of Springer Nature 2020, corrected publication 2023

\begin{abstract}
There is a current worldwide outbreak of a new type of coronavirus (2019-nCoV), which originated from Wuhan in China and has now spread to 17 other countries. Governments are under increased pressure to stop the outbreak spiraling into a global health emergency. At this stage, preparedness, transparency, and sharing of information are crucial to risk assessments and beginning outbreak control activities. This information should include reports from outbreak sites and from laboratories supporting the investigation. This paper aggregates and consolidates the virology, epidemiology, clinical management strategies from both English and Chinese literature, official news channels, and other official government documents. In addition, by fitting the number of infections with a single-term exponential model, we report that the infection is spreading at an exponential rate, with a doubling period of 1.8 days.
\end{abstract}

Keywords 2019-nCoV · Coronavirus · Wuhan · China $\cdot$ Epidemiology $\cdot$ Virology $\cdot$ Clinical guideline $\cdot$ Literature survey Review $\cdot$ Literature review $\cdot$ Novel coronavirus $\cdot$ COVID-19

\section{Introduction}

On 30th December 2019, Wuhan Municipal Health Commission (WMHC) reported 27 cases of viral pneumonia with seven of them being critically ill [35]. Most patients had a recent history of exposure to wildlife animals at the Huanan Seafood Wholesale Market in Wuhan, China, where poultry, snake, bats, and other farm animals were also sold.

This was identified to be caused by a new type of coronavirus, tentatively named 2019-nCoV by the World Health Organization (WHO). The pandemic is escalating rapidly. We searched the associated literature in both Chinese and English to summarize virology, epidemiology information; to calculate the mean doubling time value; to compare two guidelines of 2019-nCoV management (the WHO guideline

Zhangkai J. Cheng

zche2025@uni.sydney.edu.au

1 Institute of Allergy and Immunology, School of Medicine, Shenzhen University, Shenzhen, China

2 Institute of Medical Physics, University of Sydney, Sydney, Australia

3 Discipline of Child and Adolescence Health, The Faculty of Medicine and Health, University of Sydney, Sydney, Australia and the Chinese 4th edition guideline which is currently being used).

\section{Virology}

2019-nCoV is the seventh member of the family of coronaviruses that infect humans, after MERS-nCoV and SARS$\mathrm{nCoV}$. Through genome sequencing, the genetic sequence of the 2019-nCoV became available to the WHO, which enabled different laboratories to produce reverse-transcription diagnostic polymerase chain reaction (RT-PCR) test specifically for detection of viral RNA. The $2019-\mathrm{nCoV}$ is a $\beta \mathrm{CoV}$ of group 2B with over $70 \%$ similarity in genetic sequence to SARS-nCoV [1].

The source of the new coronavirus infection has been determined as bats. With full-length genome sequences, Zhou and colleagues found that $2019-\mathrm{nCoV}$ is $96 \%$ identical at the whole-genome level to a bat coronavirus [2]. Wu and colleagues performed phylogenetic analysis on the complete viral genome and deduced that the virus was most closely related to a group of SARS-like coronavirus previously sampled from bats in China [3]. Ji and colleagues performed comprehensive sequence analysis and comparison in conjunction with relative synonymous codon usage (RSCU) bias among different animal species based on the 2019-nCoV 
RNA genome sequence, and the results showed the virus to be a recombinant virus between the bat coronavirus and another coronavirus with unknown origin. They also suggested that snake is the most probable animal reservoir due to the virus's RSCU bias being closest to snake [4]. Zhu and colleagues used deep learning algorithms to analyze the gene sequences of novel coronaviruses and other coronaviruses to predict potential viral hosts. Their results indicated that bats and minks may be the two potential hosts of the novel coronavirus, while minks may be the intermediate hosts of the virus [5]. The novel coronavirus showed a similar pattern of infection to other coronaviruses in humans, particularly severe acute respiratory syndrome coronavirus (SARS-nCoV), Bat SARS-like CoV, and Middle East respiratory syndrome coronavirus (MERS-nCoV). After comparing coronaviruses in other vertebrates, the study found that the bat coronaviruses had the most similar infection patterns to the novel coronaviruses. After comparing the infection patterns of other vertebrate coronavirus hosts, the infection patterns of minks were found to be most similar to those of the novel coronavirus.

By modelling the spike protein of the receptor for 2019$\mathrm{nCoV}, \mathrm{Xu}$ and colleagues reported that angiotensin-converting enzyme 2 (ACE2) could be the receptor for this virus [6]. Similarly, ACE2 is also the receptor for SARS-nCoV and NL63 [7-9]. According to their model, the binding strength between 2019-nCoV and ACE2 is higher than the threshold required for virus infection, albeit being weaker than that between SARS-nCoV and ACE2. Zhou and colleagues conducted virus infectivity studies and showed that ACE2 is essential for 2019-nCoV to enter HeLa cells [10]. These data indicated that ACE2 is likely to be the receptor for 2019-nCoV. Zhao and colleagues analyzed normal lung tissue cells of eight healthy individuals, and found that the only Asian donor has over five times as much ACE2 expressing cell ratio than white and African American donors [11]. These results point to a possible heightened susceptibility of Asian population, although more evidence is needed to draw such conclusion.

\section{Epidemiology}

A total of 515 environment samples were collected from businesses related to the patients and their neighborhood on 1st January 2020 and transported to Institute of Viral Disease, Chinese Center for Disease Control and Prevention (CCDC) for testing. On 12th January 2020, 70 more samples from wildlife shops in the seafood market were collected for testing. PCR testing results showed that out of the 585 samples, 33 were tested positive to contain 2019-nCoV, and the virus was successfully isolated from positive samples, suggesting that the virus originated from wildlife animals sold in the seafood market in southern China [12]. However, this idea was challenged by a Lancet report detailing the first 41 infected patients who were hospitalized between 16th December 2019 and 2nd January 2020 [13], which stated "No epidemiological link was found between the first patient and later cases". Their data also showed that, in total, 13 of the 41 cases had no link to the marketplace. Speaking to Science, Daniel Lucey from Georgetown University noted that since the virus seems to have an incubation period of up to 14 days and the first reported case emerged on 1st December 2019, it is possible that the initial human infection took place in November if not earlier. If so, the virus possibly spread silently between people in Wuhan before the cluster of cases from Huanan Seafood Wholesale Market was discovered in late December $[14,15]$. Tracing the source of the virus, controlling the source and clarifying the intermediate host of the virus are the key links to control the continuous transmission of the virus from animals to people. Work is currently underway to determine possible virus reservoirs.

Person-to-person transmission of the coronavirus was confirmed by Chan and colleagues, who reported a case of five patients in a family cluster [16]. The estimates for reproduction number $R_{0}$ differ between different research teams and are constantly updated as more information comes to light. WHO has published their estimation of $R_{0}$ to be 1.4-2.5 using early information. Jonathan Read and colleagues from Lancaster University fitted a deterministic Susceptible-Exposed-Infected-Recovered (SEIR) metapopulation transmission model of infection within and between major Chinese cities to the daily number of confirmed cases of 2019-nCoV in Chinese cities and cases reported in other countries/regions, using an assumption of Poissondistributed daily time increments. They determined the $R_{0}$ to be around 3.1 [17]. Majumder and colleagues at Boston Children's Hospital used Incidence Decay and Exponential Adjustment (IDEA) model to estimate $R_{0}$ to be between 2.0 and 3.3 [18]. A large group of researchers from multiple institutes led by Jianhong Wu from York University proposed a more general deterministic SEIR compartmental model using more parameters, and arrived at a much higher $R_{0}$ number of 6.47 [19]. Li and colleagues analyzed data on the first 425 confirm cases in Wuhan and found that $R_{0}$ to be 2.2, without specifying their modelling method [15]. Table 1 compares the $R_{0}$ values from studies conducted by different groups.

According to National Health Commission in China [24], 9692 confirmed cases, 15,238 suspected cases, 213 deaths and 171 cures have been announced as on 31st January 2020. The number of confirmed cases has surpassed SARS in 2003. The actual number of cases is likely to be much higher as the confirmation is severely limited by the number of PCR test kits as well as staff available in each hospital. Figure 1a traces the number of confirmed cases, suspected cases 
Table $1 R_{0}$ Estimations from different groups

\begin{tabular}{llll}
\hline Group & $R_{0}$ & Date & Source \\
\hline WHO & $1.4-2.5$ & 23 Jan & {$[20]$} \\
Majumder & $2.0-3.3$ & Updated 27 Jan & {$[18]$} \\
Althaus & $2.2(90 \%$ CI 1.4-3.8) & 25 Jan & {$[21]$} \\
Tang & 6.47 (95\% CI 5.71-7.23) & 24 Jan & {$[19]$} \\
Read & $3.11(90 \%$ CI 2.39-4.13) & Updated 27 Jan & {$[17]$} \\
Leung & $2.13(1.92-2.31)$ & 25 Jan & {$[22]$} \\
Gardner & 2 & 26 Jan & {$[23]$} \\
Li & $2.2(95 \%$ CI 1.4-3.9) & 29 Jan & {$[15]$} \\
\hline
\end{tabular}

and deaths and cured in China over time, with data taken from the past daily statements of National Health Commission [24]. Figure 1b shows that the virus is spreading at an exponential speed after 16th January 2020, evident from the number of confirmed cases increases linearly with log scale. Using a single-term exponential model, we yielded a high $R^{2}$ value of 0.95 . The exponent is 0.38 , meaning that the infected population doubles in size around every 1.8 days. A divergence from the exponential fit is observed at the data point on the 31st January 2020, and we expect further divergence in the future, due to the effect of the new quarantine measures starting to take place.

Currently (31st January 2020), the virus has been spread to 17 other countries [25], with number of confirmed cases: Thailand (14), Japan (11), Singapore (10), Australia (9), Malaysia (8), USA (6), France (5), Germany (5), Korea (4), United Emirates (4), Canada (3), Vietnam (2), Nepal (1), Finland (1), Sri Lanka (1), India (1), and Cambodia (1). Using back-calculation method, Nishiura has estimated the cumulative incidence in China in real time, allowing us to update and discuss the extent of transmission at the source [26].

All age groups can be infected. According to Bin Cao, the Executive vice President at the Institute of Respiratory Medicine, Chinese Academy of Medical Sciences, $72 \%$ confirmed infection cases are aged 40 and above, $64 \%$ are male. $40 \%$ patients also have other underlying diseases such as diabetes and high blood pressure [27].

\section{Modeling the spread}

Lauren Gardner from Johns Hopkins University led a team of researchers to model the real-time spread of the coronavirus. The team's new analysis was based on a model, the outbreak boundary control decision support framework, released last December, which integrates the dynamics of the outbreak and outbreak control of the new coronavirus pneumonia into a decision support tool to facilitate border control in the early stages of an outbreak to mitigate further spread. The team used a random set of population epidemic simulation tools to simulate the dynamics of the epidemic, and considered the border protection mechanism (immigration inspection) in the modeling process, which is mainly used to identify infected people or high-risk groups [23]. The aggregation population model is mainly constructed based on the population network, which is divided into urban and intercity parts, and the edge of the network is the air line between different cities. At each node of the network, the researchers used a discrete-time Susceptible-ExposedInfected-Recovered (SEIR) model to simulate the dynamics of an outbreak.

The researchers were able to observe a lot of interesting information from the model, which ran from the start of

\section{(a)}

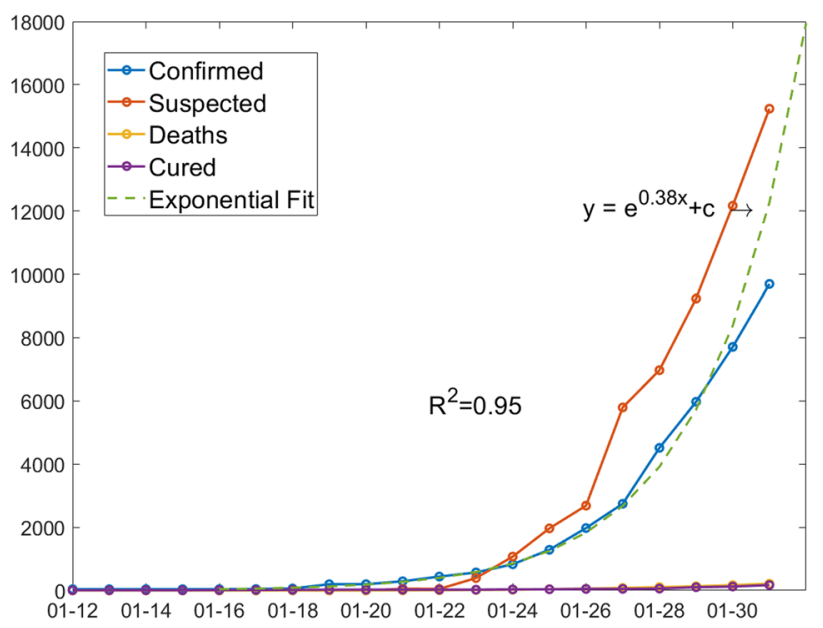

(b)

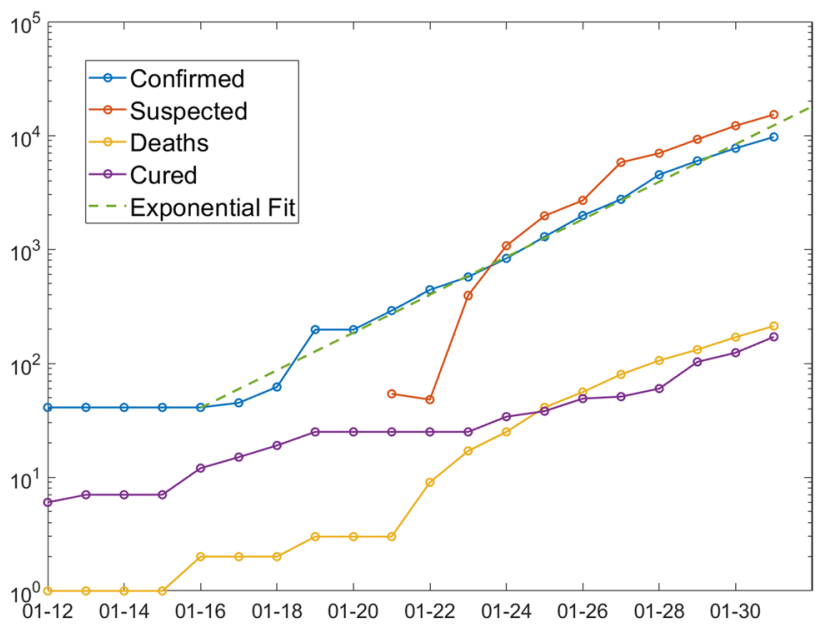

Fig. 1 Number of confirmed cases, suspected cases, deaths, and cure in China over time. a Normal $y$-axis. b log-scale $y$-axis 
the outbreak until 25th January. Specifically, the researchers estimated that as of 25th January, 40 cases of 2019$\mathrm{NCoV}$ had been exported from China. At the same time, the team estimated that the number of 2019-nCoV cases in China may have been much higher than reported for the whole of January, up to about 20,000 cases of 2019-nCoV in the country as of 25th January 25 (the number reported at the time was nearly 2000). Researchers also estimated that hundreds of people in Wuhan were infected in early December. The model is, however, limited by many factors, as explained by the team on their blog post. They are primarily due to the numbers being used are conservative estimates, the transmission of 2019-nCoV, such as the $R_{0}$ value and incubation period, being uncertain, asymptomatic infections are not covered and only air travel was included [23].

\section{Clinical guidelines}

\section{Severity definitions}

We compare the severity definitions between the WHO [28] and Chinese 4th edition guidelines [29]. The categories of the severity of 2019-nCoV infection are very different in two guidelines. The WHO guideline shows five levels of severity: mild, severe, acute respiratory distress, sepsis, and septic shock. It covers both the adult and child age groups. The children one is from $<2$ months to 5 years old. From mild to acute respiratory distress levels, the respiratory rate and $\mathrm{SpO}_{2}$ are two important parameters for judging patients' clinical condition. For sepsis in adults, the patients' mental, circulating, and respiratory parameters are recommended to rank the severity; while in children, the definition of the systemic inflammatory response syndrome (SIRS) are used. In the septic shock adult patients, hypotension in adults is a substantial sign or vasopressor maintenance for mean atrial pressure $\geq 65 \mathrm{mmHg}$ with lactate level $>2 \mathrm{mmol} / \mathrm{L}$. In the septic shock for children, the criteria are based on the guideline of hemodynamic support of paediatric and neonatal Septic Shock from the American College of Critical Care Medicine [30].

The Chinese 4th edition defined three levels of severity: mild, severe, and life-threatening. The parameters are simpler than those of the WHO. Mild category is without any particular parameters; respiratory rate and $\mathrm{SpO}_{2}$ are recommended for severe-level evaluation, and it is similar to the parameters for mild-to-acute respiratory distress levels in the WHO guideline. Life-threatening level is considered when patients need mechanical ventilation, or presents as shock or multiple organ dysfunction syndrome, or requires intensivecare unit admission (Table 2).

\section{Management guidelines}

In the WHO guideline, the oxygen and intravenous fluid treatments are recommended to mild and severe cases. The targets are $\mathrm{SpO}_{2} \geq 90 \%$ in non-pregnant adult or child, and $\mathrm{SpO}_{2} \geq 92-95 \%$ in pregnant patients. Mechanical ventilation is recommended in the both adults and children with acute respiratory distress syndrome. The tide volume is recommended from $6 \mathrm{ml} / \mathrm{kg}$. Hypercapnia is acceptable and longer than $12 \mathrm{~h}$ ventilation per day is suggested to use in severe ARDS cases. The treatments of sepsis and septic shock are following the 2016 international guideline of sepsis and septic shock [31].

In the Chinese 4th edition, anti-virus medicine is recommended to use in the patient with 2019-nCoV infection. Mechanical ventilation is recommended to use in severe and life-threatening cases. Extracorporeal membrane oxygenation (ECMO) can be used to reduce pulmonary impairment during the treatment period (Table 3).

\section{Discussion}

How easily does 2019-nCoV spread, and how deadly is the virus? At the moment, we only have informed guesses, which are likely to solidify in the coming weeks and months. But what we know so far can shed some light on the characteristics of the virus, and offer some instructions on dealing with the rapidly growing pandemic. China's health authorities and the government have been moving quickly. In response to the spreading virus, isolation strategy has been used. Many cities including Wuhan have been put on quarantine since 23rd January, 2020, when millions of Chinese traditionally travel due to Lunar New Year. Planes, trains, ferries, subways, and buses cease operation, and roads in and out of the cities were closed. Residents were encouraged to wear masks in public. Many places that usually attract a large crowd, such as cafes, bars, and cinemas in many cities, Disneyland in both Shanghai and Hongkong, Forbidden City in Beijing, are now closed until further notice. We will not know for some time the consequences of the quarantine measures.

Multiple research groups studying the disease around the world are providing different values on $R_{0}$, using results obtained from their respective models. Morbidity varies in different environments, depending on factors like temperature, population density, and susceptibility to a disease in a population, so $R_{0}$ would change accordingly over time. More reliable and accurate $R_{0}$ value should appear as more information comes to light. We calculated that the number of confirmed infections after 16th January 2020 grows at an exponential rate, with a doubling time of 1.8 days. This result is significantly different from the doubling time of 
2019 Novel coronavirus: where we are and what we know

159

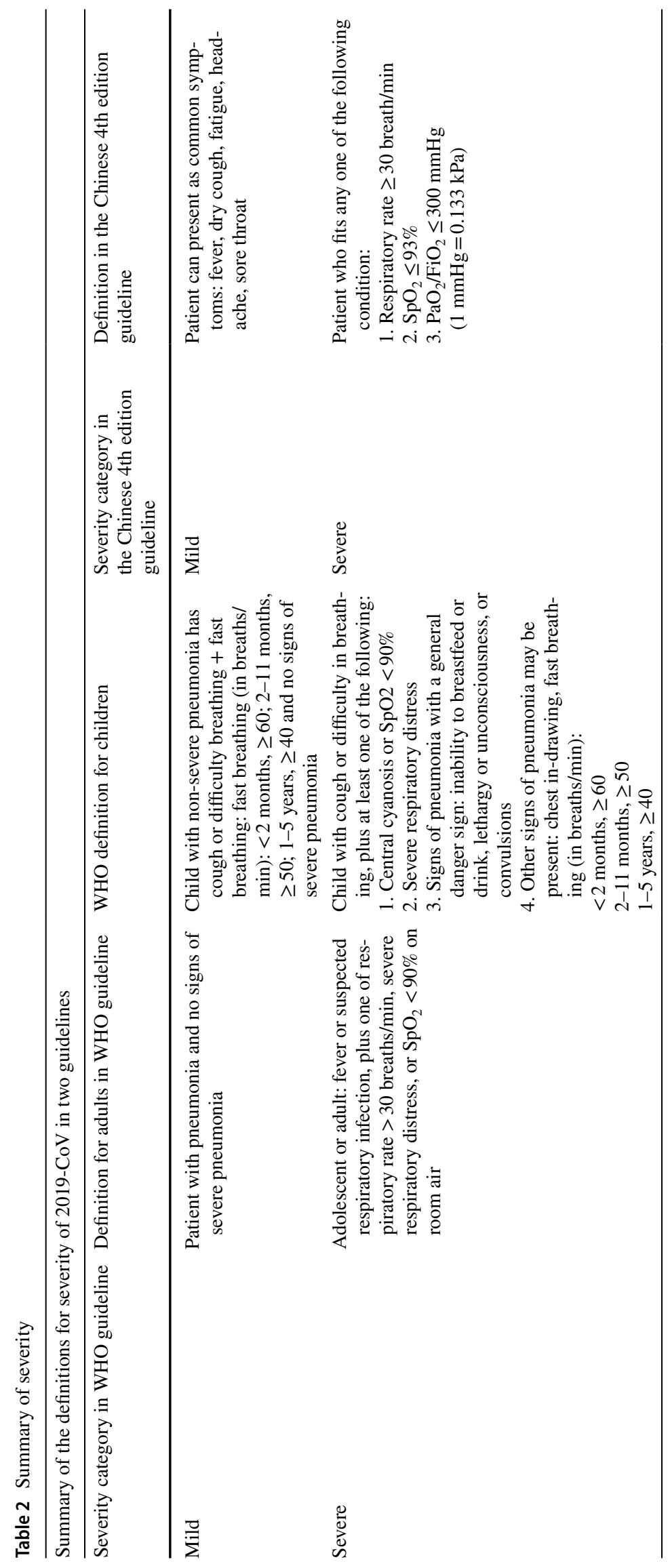

Springer 


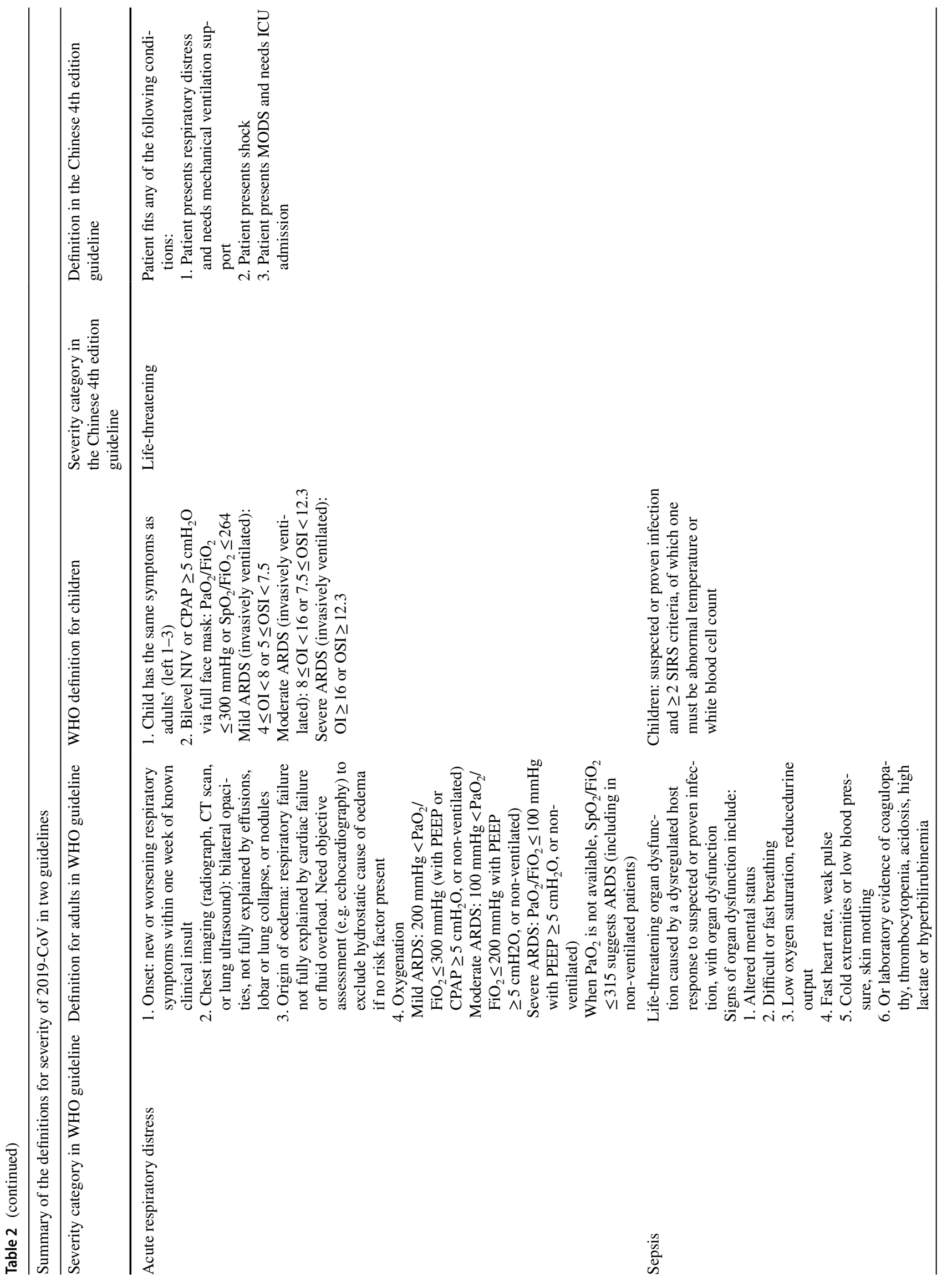




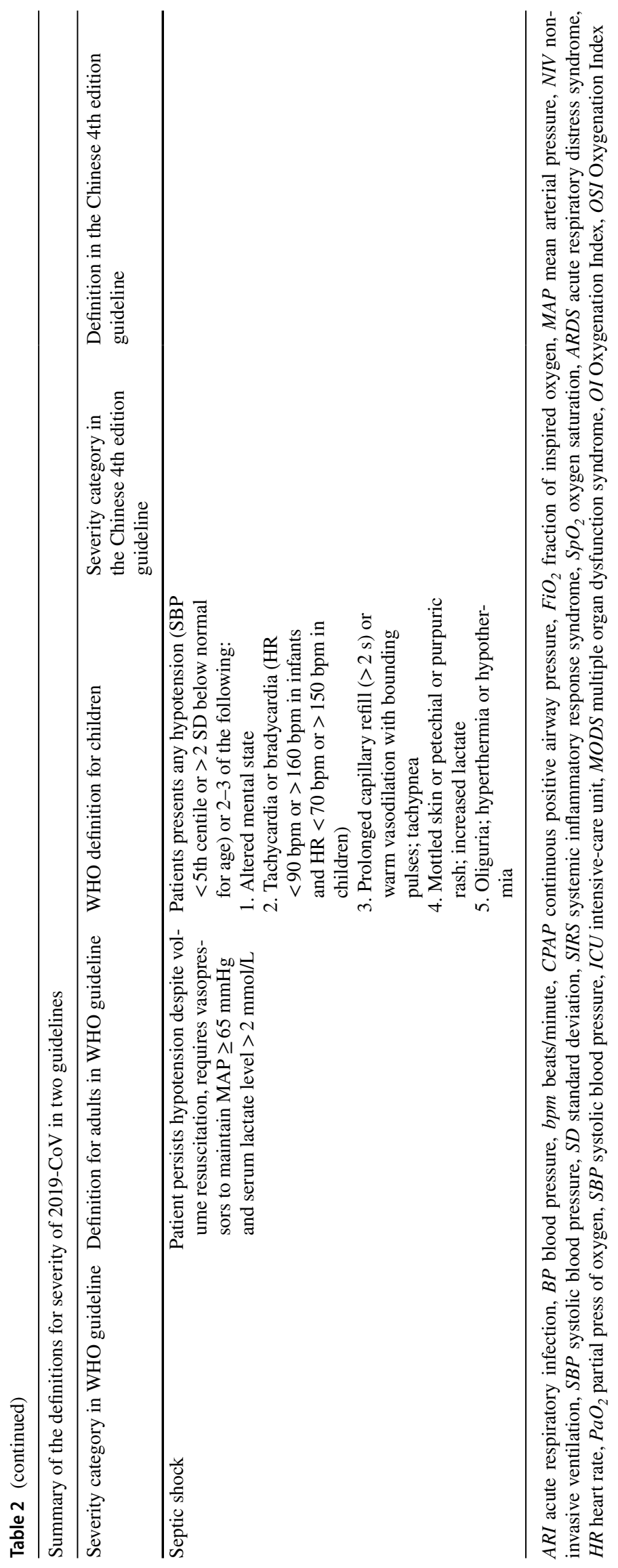




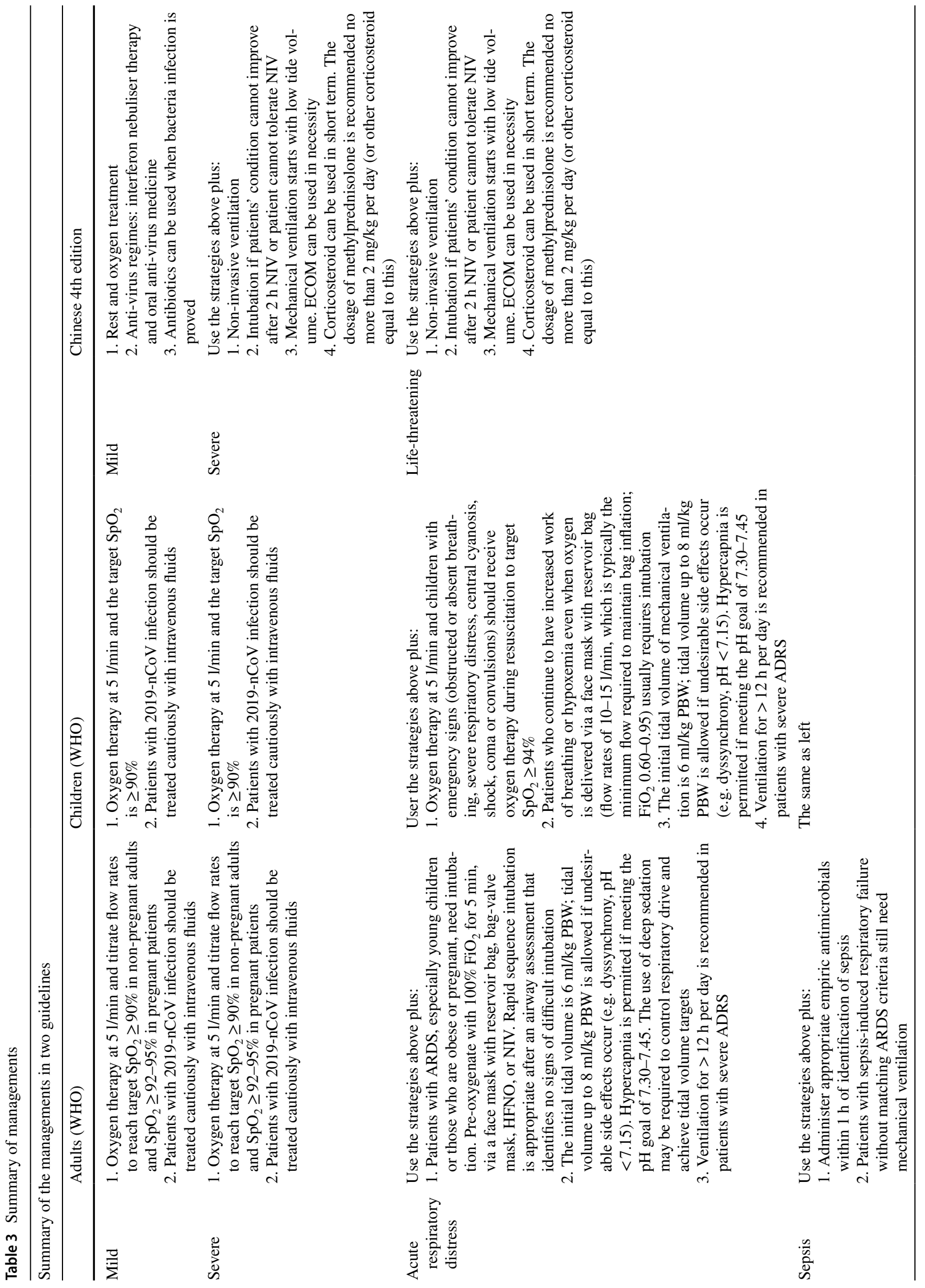




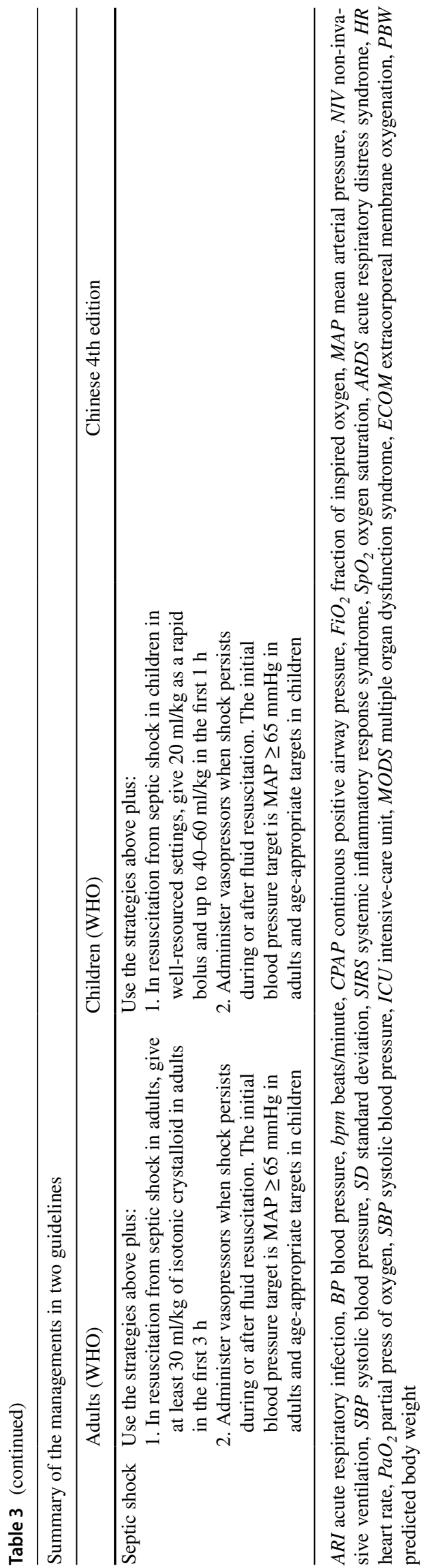

7.4 days found in Li's group, which was obtained from analyzing the cases before 4th January 2020. This might be due to several factors: at early stages, the lack of awareness for the disease and lack of detection methods would have hindered the disease detection and confirmation. Low number of confirmed cases would result in high uncertainty of the calculation. At later stages, the increase in availability of PCR test kits and other clinical resources would result in higher confirmation rate than the true value.

Virology results indicate that some Asian populations may potentially be more susceptible to $2019-\mathrm{nCoV}$ than other races $[6,10,11]$, which is consistent with the observation that disproportionally higher number of Asian populations is infected, even in an international metropolitan like Shanghai, although more evidence is needed to draw such conclusion. Chen and colleagues found a greater number of men than women in the 99 cases of $2019-\mathrm{nCoV}$ which they reported. In previous SARS and MERS outbreaks, men were also more likely to be infected than women [32]. This may have to do with the important role that both woman's X chromosomes and sex hormones play in the body's immune system [33]. Their study also suggests that older men with chronic diseases are more likely to be infected with the new coronavirus because of their weakened immune system.

The major difference between the WHO [28] and Chinese 4th edition guideline [29] is the standard in treating children with 2019-nCOV infection. Until now, a few cases of children infected have been reported with the youngest one is 10 years old. ARDS is a common symptom in the 2019-nCoV infection cases. $\mathrm{SpO}_{2}$ and respiration rate check became very important in the clinical practice. Mechanical ventilation is a major treatment of it, and it has been recommended in both guidelines. The low tidal volume, plateau pressure limitation, no oscillatory ventilation, and prone position have been evidenced as high proof [34]. The anti-virus medicine is recommended in the Chinese 4th edition. A recent publication reported 99 cases in Jinyin-Tan hospital were given anti-virus medicine such as oseltamivir (75 mg every $12 \mathrm{~h}$, orally), ganciclovir $(0.25 \mathrm{~g}$ every $12 \mathrm{~h}$, intravenously), and lopinavir and ritonavir tablets $(500 \mathrm{mg}$ twice daily, orally), and the influence of the outcome has been mentioned in detail [32]. Short-term corticosteroids use is recommended in the Chinese 4th edition, the aim of which is to reduce the self-damage by over-reactive immune response. Antibiotic use is recommended when the patient has evidence of bacterial infection. Some patients in the 99 cases presented a rapid progress to ARDS, and the benefits of short-term use of methylprednisolone $1-2 \mathrm{mg} / \mathrm{kg}$ per day and intravenous immunoglobulin were observed in these patients [32]. These two guidelines are currently being used; however, some of the contents are still controversial, especially the benefits of steroids and antibiotic. Further study should be continued in the clinical practice. Our summary 
of WHO guidelines just included recommended contents. The controversial contents are excluded.

\section{Compliance with ethical standards}

Conflict of interest On behalf of all authors, the corresponding author states that there is no conflict of interest.

\section{References}

1. Hui DS, Azhar E, Madani TA, Ntoumi F, Kock R, Dar O, et al. The continuing 2019-nCoV epidemic threat of novel coronaviruses to global health - the latest 2019 novel coronavirus outbreak in Wuhan, China. Int J Infect Dis. 2020;91:264-6.

2. Zhou P, Yang X-L, Wang X-G, Hu B, Zhang L, Zhang W, et al. A pneumonia outbreak associated with a new coronavirus of probable bat origin. Nature. 2020 (in press).

3. Wu F, Zhao S, Yu B, Chen Y-M, Wang W, Song Z-G, et al. A new coronavirus associated with human respiratory disease in China. Nature. 2020.

4. Ji W, Wang W, Zhao X, Zai J, Li X. Homologous recombination within the spike glycoprotein of the newly identified coronavirus may boost cross-species transmission from snake to human. J Med Virol. 2020.

5. Guo Q, Li M, Wang C, Wang P, Fang Z, Tan J, et al. Host and infectivity prediction of Wuhan 2019 novel coronavirus using deep learning algorithm. bioRxiv. 2020.

6. Xu X, Chen P, Wang J, Feng J, Zhou H, Li X, et al. Evolution of the novel coronavirus from the ongoing Wuhan outbreak and modeling of its spike protein for risk of human transmission. Sci China Life Sci. 2020;63.

7. Li W, Sui J, Huang I-C, Kuhn JH, Radoshitzky SR, Marasco WA, et al. The S proteins of human coronavirus NL63 and severe acute respiratory syndrome coronavirus bind overlapping regions of ACE2. Virology. 2007;367:367-74.

8. Wu K, Li W, Peng G, Li F. Crystal structure of NL63 respiratory coronavirus receptor-binding domain complexed with its human receptor. Proc Natl Acad Sci USA. 2009;106:19970-4.

9. He L, Ding Y, Zhang Q, Che X, He Y, Shen H, et al. Expression of elevated levels of pro-inflammatory cytokines in SARS-CoVinfected ACE2+ cells in SARS patients: relation to the acute lung injury and pathogenesis of SARS. J Pathol. 2006;210:288-97.

10. Zhou P, Yang X-L, Wang X-G, Hu B, Zhang L, Zhang W, et al. Discovery of a novel coronavirus associated with the recent pneumonia outbreak in humans and its potential bat origin. bioRxiv. 2020.

11. Zhao Y, Zhao Z, Wang Y, Zhou Y, Ma Y, Zuo W. Single-cell RNA expression profiling of ACE2, the putative receptor of Wuhan 2019-nCov. bioRxiv preprint. 2020.

12. Xinhua. http://www.xinhuanet.com/2020-01/27/c_1125504355. htm; 2020.

13. Huang C, Wang Y, Li X, Ren L, Zhao J, Hu Y, et al. Clinical features of patients infected with 2019 novel coronavirus in Wuhan, China. Lancet. 2020 (in press).

14. Lucey D. https://www.sciencemag.org/news/2020/01/wuhan-seafo od-market-may-not-be-source-novel-virus-spreading-globally; 2020.

15. Li Q, Guan X, Wu P, Wang X, Zhou L, Tong Y, et al. Early transmission dynamics in Wuhan, China, of novel coronavirus-infected pneumonia. N Engl J Med. 2020 (in press).

16. Chan JF, Yuan S, Kok KH, To KK, Chu H, Yang J, et al. A familial cluster of pneumonia associated with the 2019 novel coronavirus indicating person-to-person transmission: a study of a family cluster. Lancet. 2020 (in press).

17. Read JM, Bridgen JRE, Cummings DAT, Ho A, Jewell CP. Novel coronavirus 2019-nCoV: early estimation of epidemiological parameters and epidemic predictions. Available at medRxiv preprint; 2020.

18. Majumder M, Mandl KD. Early transmissibility assessment of a novel coronavirus in Wuhan, China. Available at SSRN; 2020.

19. Tang B, Wang X, Li Q, Bragazzi NL, Tang S, Xiao Y, et al. Estimation of the transmission risk of 2019-nCov and its implication for public health interventions. Available at SSRN; 2020.

20. WHO. Statement on the meeting of the International Health Regulations (2005) Emergency Committee regarding the outbreak of novel coronavirus (2019-nCoV); 2020.

21. Althaus C. https://twitter.com/C Althaus/ status/1220723566272045057?ref_src=twsrc\%5Etfw\%7Ctwca mp\%5Etweetembed\%7Ctwterm\%5E1220723566272045057\& ref_url=https $\% 3 \mathrm{~A} \% 2 \mathrm{~F} \% 2 \mathrm{Fwwwvoxcom} \% 2 \mathrm{~F} 2020 \% 2 \mathrm{~F} 1 \% 2 \mathrm{~F} 28$ $\% 2 \mathrm{~F} 21079946 \% 2 \mathrm{Fcoronavirus-china-wuhan-deaths-pandemic;}$ 2020.

22. Leung $\mathrm{G}, \mathrm{Wu}$ J. Real-time nowcast and forecast on the extent of the Wuhan CoV outbreak, domestic and international spread. Media Conference 27 January; 2020.

23. Gardner L. Modeling the Spread of 2019-nCoV. https://systemsjhuedu/wp-content/uploads/2020/01/Gardner-JHU_nCoV-Modeling-Report_Jan-26pdf; 2020.

24. NHC. 疫情通报. http://www.nhc.gov.cn/xcs/yqtb/list_gzbd.shtml; 2020.

25. DXY. 疫情地图. https://3g.dxy.cn/newh5/view/pneumonia?from= timeline\&isappinstalled $=0 ; 2020$.

26. Nishiura H, Jung Sm, Linton NM, Kinoshita R, Yang Y, Hayashi $\mathrm{K}$, et al. The extent of transmission of novel coronavirus in Wuhan, China, 2020. J Clin Med. 2020;9:330.

27. Xinhua. http://www.xinhuanet.com/politics/2020-01/28/c_11255 06707.htm; 2020.

28. Guidance W. Clinical management of severe acute respiratory infection when novel coronavirus $(2019-\mathrm{nCoV})$ infection is suspected. WHO; 2020.

29. Guidance C. 新型冠状病毒感染的肺炎诊疗方案 (试行第四 版). https://www.gov.cn/zhengce/zhengceku/2020-01/28/54726 73/files/0f96c10cc09d4d36a6f9a9f0b42d972b.pdf; 2020.

30. Davis AL, Carcillo JA, Aneja RK, Deymann AJ, Lin JC, Nguyen TC, et al. American College of Critical Care Medicine Clinical Practice Parameters for Hemodynamic Support of Pediatric and Neonatal Septic Shock. Crit Care Med. 2017;45:1061-93.

31. Rhodes A, Evans LE, Alhazzani W, Levy MM, Antonelli M, Ferrer R, et al. Surviving sepsis campaign: international guidelines for management of sepsis and septic shock: 2016. Intensive Care Med. 2017;43:304-77.

32. Chen N, Zhou M, Dong X, Qu J, Gong F. Epidemiological and clinical characteristics of 99 cases of 2019 novel coronavirus pneumonia in Wuhan, China: a descriptive study. Lancet. 2020 (in press).

33. Jaillon S, Berthenet K, Garlanda C. Sexual dimorphism in innate immunity. Clin Rev Allergy Immunol. 2019;56:308-21.

34. Papazian L, Aubron C, Brochard L, Chiche JD, Combes A, Dreyfuss $\mathrm{D}$, et al. Formal guidelines: management of acute respiratory distress syndrome. Ann Intensive Care. 2019;69.

35. Wuhan Municipal Health Commission. 武汉市卫健委关于当前 我市肺炎疫情的情况通报. 2019. http://wjw.wuhan.gov.cn/gsgg/ 202004/t20200430_1199576.shtml. 